\title{
Behavioral mechanisms underlying the refuge value of benthic habitat structure for two flatfishes with differing anti-predator strategies
}

\author{
Clifford H. Ryer*, Allan W. Stoner, Richard H. Titgen \\ Fisheries Behavioral Ecology Program, Alaska Fisheries Science Center, National Marine Fisheries Service/ \\ National Oceanic \& Atmospheric Association (NMFS/NOAA), Hatfield Marine Science Center, Newport, Oregon 97365, USA
}

\begin{abstract}
Juvenile flatfish habitat is usually modeled on the basis of sediment grain-size, depth and temperature. Recent evidence indicates that some juvenile flatfishes associate with emergent structures such as sponge, shell and other biogenic and bed-form features of otherwise low-relief shelf habitats. In laboratory experiments we examined the habitat preference and effects of habitat structure upon predation vulnerability of sub-yearling (Age-0) Pacific halibut Hippoglossus stenolepis and northern rock sole Lepidopsetta polyxystra. When given the choice between bare sand or sand with $16 \%$ sponge coverage, halibut demonstrated strong preference for sponge, while rock sole showed no preference. Larger Age-2 halibut (used as predators in the subsequent experiment) also preferred sponge, but this preference declined with increasing hunger. When allowed to forage for Age-0 flatfishes in either bare sand or sponge, predators consumed more prey in sand and consumed more Age-0 halibut than rock sole. We were able to determine which behavioral processes in the predator-prey interaction were modified by the presence of habitat structure. Predator-prey encounter rates decreased in the sponge habitat as predator search was impeded: predators paused more frequently and swam more slowly to maneuver through the sponges. Sponges also tended to hinder the pursuit of prey. Rock sole utilized stereotypic flatfish defense-mechanisms, relying upon immobility, burial and crypsis, and were less likely to flush at a predator's approach than halibut. Halibut have a less developed ability to mimic sediments, but a deeper/narrower body that confers greater swimming speed, and were more likely to flush as a predator approached. Once they had flushed and were pursued by a predator, halibut were more likely to escape than were rock sole. These experiments support an accumulating body of evidence that emergent structure, in otherwise low-relief benthic habitats, may play an important role in the ecology of some juvenile flatfishes. Removal of emergent structure by towed fishing gear and other anthropogenic and/or natural disturbance may influence patterns of distribution for juvenile halibut, as fish redistribute to less preferred habitat, and may decrease survival rates through increased losses to predation.
\end{abstract}

KEY WORDS: Habitat complexity · Pacific halibut $\cdot$ Rock sole $\cdot$ Predator-prey interaction $\cdot$ Behavior $\cdot$ Essential fish habitat

Resale or republication not permitted without written consent of the publisher

\section{INTRODUCTION}

Flatfish antipredator strategies depend upon the fish's ability to cryptically match the appearance of sediments and its ability to bury in sediments. Since sediment characteristics also control the composition of the infaunal and epifaunal communities upon which juvenile and many adult flatfishes forage, sediment characteristics have traditionally been viewed as a primary factor, along with temperature and depth, in flatfish habitat selection (Rogers 1992, Swartzman et al. 1992, Jager et al. 1993, Abookire \& Norcross 1998, Norcross et al. 1999, McConnaughey \& Smith 2000, Amezcua \& Nash 2001, Stoner \& Abookire 2002). 
While some species, such as yellowfin sole Pleuronectes asper and plaice $P$. platessa, show little sizerelated sediment preference (Moles \& Norcross 1995, Gibson \& Robb 2000), other species, such as starry flounder Platichthys stellatus, winter flounder Pseudopleuronectes americanus, Pacific halibut Hippoglossus stenolepis and northern rock sole Lepidopsetta polyxystra, exhibit shifts in sediment preference during their first year (Moles \& Norcross 1995, Phelan et al. 2000, Stoner \& Ottmar 2003). For species demonstrating ontogenetic shifts, smaller juveniles generally prefer finer sediments than do larger juveniles and adults. This is in part due to a positive relationship between body size and the ability to bury in coarse sediments (Gibson \& Robb 1992), and has been related to the rapid ontogenetic progression of sediment preference by some species during their first year (Stoner \& Ottmar 2003). However, food availability can override preference for grain size, suggesting that a complex interaction of factors potentially influences habitat preference (Phelan et al. 2001).

Emergent structures in soft-sediment environments, such as shells, cobble, burrows, feeding pits and sand waves, provide structural complexity in an otherwise low-relief bottom. Recent studies indicate that a variety of mobile megafauna, both fishes and crustacean, associate with these structural components (Auster et al. 1996, Thrush et al. 2002). Among flatfishes, a good example of this type of association is found in juvenile winter flounder Pseudopleuronectes americanus. Stoner et al. (2001) demonstrated that although winter flounder initially recruit to muddy sediments, by the time they reach $55 \mathrm{~mm}$ total length they are often associated with drift algae Ulva lactuca and Gracilaria sp. in shallow water (1 to $3 \mathrm{~m}$ ) (see also Sogard \& Able 1991). These larger juveniles can also be associated with woody debris and shells (Howell et al. 1999). Structurally complex benthic habitats have been demonstrated to alleviate predation risk for a wide variety of organisms in diverse systems (Savino \& Stein 1982, Stoner 1982, Ryer 1988, Ryer et al. 1990). Similarly, laboratory experiments indicate that winter flounder are less vulnerable to predation in vegetated habitats (Manderson et al. 2000), but whether the observed preference for structured habitats is rooted in refuge or foraging value remains equivocal (Sogard 1992).

In Alaskan waters, flatfish species play an important ecological role and support a large commercial fishery. While several studies have examined the role of depth and sediment characteristics in juvenile $(<1 \mathrm{yr})$ flatfish distribution, these studies have been limited to relatively small geographic regions near Kodiak Island (Norcross et al. 1997, 1999) and Kachemak Bay, Alaska (Abookire \& Norcross 1998, Stoner \& Abookire 2002). Other than anecdotal references (Norcross \& Mueter
1999), little attention has been given to the role of structure in the habitat requirements of juvenile Pacific flatfishes. We have observed that the abundance of Age-0 halibut Hippoglossus stenolepis and northern rock sole Lepidopsetta polyxystra is positively correlated with the abundance of shells and macroinvertebrates in Chiniak Bay, Kodiak Island, Alaska (Stoner \& Titgen 2003). Further, laboratory studies have demonstrated a strong preference by Age-0 Pacific halibut for habitats containing shell, sponge, imitation bryozoans and bed-form features such as sand waves, with Age-0 northern rock sole expressing a positive, but lesser preference for these habitat features (Stoner \& Titgen 2003). In the Bering Sea, some of the highest densities of sessile invertebrates, such as sponges and bryozoans, occur in the southeast region, north of the Alaskan Peninsula (NOAA, see www.afsc.noaa.gov/groundfish/HAPC/ EBScontents.htm). Much of this area is considered by the International Pacific Halibut Commission to be a nursery ground for juvenile halibut, and has a complex history of trawl prohibitions extending from 1959 to the present (McConnaughey et al. 2000).

This study examined the habitat preferences of 2 North Pacific juvenile flatfishes, the Pacific halibut and northern rock sole (hereafter halibut and rock sole), relative to bare sand bottom and a sand bottom with sponge. We present the results of predation experiments designed to address whether structurally complex benthic habitats (sponge) may influence the vulnerability of juvenile halibut and rock sole to predation. We focus upon determining what aspects of the predator-prey behavioral interaction are affected by habitat structure, as well as differences between juvenile halibut and rock sole in their antipredator behaviors.

\section{MATERIALS AND METHODS}

Fish collection and maintenance. Age- 0 halibut and rock sole (<70 mm total length) were collected with a beam trawl ( $2 \mathrm{~m}$ wide, $3 \mathrm{~mm}$ mesh) towed at $\sim 50 \mathrm{~cm} \mathrm{~s}^{-1}$ in Chiniak Bay, Kodiak Island, Alaska $\left(57^{\circ} 40^{\prime} \mathrm{N}\right.$, $152^{\circ} 30^{\prime} \mathrm{W}$ ) in June and August 2001. Age-2 halibut (13 to $17 \mathrm{~cm}$ ) were collected as Age-1 juveniles in the same locality in August 2000 and grown out in the laboratory. The fish were maintained at the Kodiak Fisheries Research Center for 2 to $3 \mathrm{~d}$ prior to air transport to the NMFS laboratory at the Hatfield Marine Science Center in Newport, Oregon. Few fish died during transport, and most fed within $24 \mathrm{~h}$ of arrival, indicating good health and low stress levels.

Age-2 halibut were maintained in 64001 tanks at the Newport facility, and Age-0 rock sole and halibut were 
held in square $159 \mathrm{l}$ tanks, measuring $75 \mathrm{~cm}$ on each side. All tanks had a thin layer of sand on the bottom and flow-through seawater averaging $9^{\circ} \mathrm{C}( \pm 1)$. Age- 0 halibut and rock sole were fed to satiation thrice weekly on a diet of gel food comprised of squid, herring, krill, amino acid supplements and vitamins. Age2 halibut were fed thrice weekly on a diet of gel food as well as whole squid Loligo spp. To reacquaint them with live prey, $4 \mathrm{wk}$ prior to the initiation of predation trials, the diet of Age-2 halibut predators was expanded to include live Age-0 English sole Parophrys vetulus. We assume that training our Age-2 halibut predators with Age-0 English sole did not predispose them to display differential success in their foraging for either Age-0 halibut or rock sole during the predation experiment.

Age-0 halibut and rock sole habitat-preference experiments. Habitat-preference trials were conducted in $2.9 \mathrm{~m}$ diameter circular arenas provided with flow-through $9^{\circ} \mathrm{C}( \pm 1)$ seawater to a depth of $1 \mathrm{~m}$. The entire bottom of each arena was covered with a 2:1 mixture of coarse $(1.0 \mathrm{~mm})$ and medium $(0.5 \mathrm{~mm})$ sand to a depth of $3 \mathrm{~cm}$, which allowed juvenile flatfishes to bury completely. The sand was raked smooth before each trial, and then 1 side of each arena was randomly selected to receive 52 sponges in an approximately uniform pattern. A commercial sponge (Hippospongia sp.), weighed down with a stainless-steel nut, was used to mimic Halichondria sp., a sponge that is common in the Bering Sea. These spherical to elliptical sponge skeletons provided a low, solid profile (mean length = $6.3 \mathrm{~cm}$, width $=5.3 \mathrm{~cm}$, area $=105 \mathrm{~cm}^{2}$ ) similar in size and shape to Halichondria sp. Sponge density was $15 \mathrm{~m}^{-2}$ or $16 \%$ aerial coverage on 1 side of the arena. The combined bycatch of sponges, anemones and tunicates in the southeastern Bering Sea is often $430 \mathrm{~kg} \mathrm{ha}^{-1}$ (see: www.afsc.noaa.gov/groundfish/HAPC/EBScontents.htm). Sponge is the largest contributor to this weight, and assuming the trawl captures $10 \%$, with a sponge-specific gravity of $1.2 \mathrm{~g} \mathrm{~cm}^{-3}$, this translates to a cube $7.1 \mathrm{~cm}$ on a side for each $\mathrm{m}^{-2}$, or approximately 1 sponge $\mathrm{m}^{-2}$. Since the catch retained by a trawl is an average of density over the distance towed, and macroinvertebrates are often patchily distributed, we assumed that 15 sponges $\mathrm{m}^{-2}$ would approximate highdensity patches of sponge in the field. Both Age-0 halibut and rock sole were starved for $48 \mathrm{~h}$ prior to the initiation of habitat-preference trials. This starvation period was adopted after preliminary trials had indicated that juveniles fed within $24 \mathrm{~h}$ of introduction to arenas would often remain stationary, failing to move about and sample the available habitats. Prior $(4 \mathrm{~h})$ to the initiation of each trial, 18 fishes were introduced into a $62 \mathrm{~cm}$ diameter plexiglass ring positioned in the center of each arena so that it encompassed equal por- tions of both the sand and sponge habitats. At 13:00 h the trial was initiated by raising and removing the ring from the tank. Preference trials continued until 13:00 h the next day. The fishes were accustomed to a $12: 12 \mathrm{~h}$ photoperiod (with darkness from 19:00 to 07:00 h), which was continued during preference trials. Light levels in the room containing the arenas were $3 \mu \mathrm{mol}$ photons $\mathrm{m}^{-2} \mathrm{~s}^{-1}$ during the day and $<1 \times 10^{-8} \mu \mathrm{mol}$ photons $\mathrm{m}^{-2} \mathrm{~s}^{-1}$ during the night. No observations on fish behavior were made during these trials. To terminate a trial, a divider was lowered from the ceiling to separate the 2 habitat types and prevent the fishes from changing sides. Then the water level was lowered to approximately $10 \mathrm{~cm}$ to allow us to enter the arena, remove the sponges, recover and then measure the fishes. To recover fishes, each side of the arena was methodically raked 3 times, by 3 different persons, dip-netting the fishes as they moved. In all trials this resulted in complete recovery of Age- 0 flatfishes. We conducted 8 trials each for halibut and rock sole. Age- 0 rock sole were, on average, $4 \mathrm{~mm}$ smaller than halibut $\left(F_{1,28}=\right.$ 8.92, $\mathrm{p}=0.006$, halibut: 32 to $84 \mathrm{~mm}, \bar{x}=59.4, \mathrm{SE}=0.9$; rock sole: 40 to $82 \mathrm{~mm}, \bar{x}=55.3, \mathrm{SE}=0.7$ ). Fish size had no effect upon habitat preference $\left(F_{1,28}=1.49, \mathrm{p}=\right.$ 0.232). Data on habitat occupancy were analyzed using G-tests (Sokal \& Rohlf 1969), first testing for heterogeneity, then for deviation from a 50:50 frequency distribution between habitats.

Age-2 halibut preference-experiment. For Age-2 halibut trials, arenas were set up with the same sand/sponge habitat arrangement as for Age-0 trials. In each of 5 arenas, 6 fish were monitored for habitat preference over $2 \mathrm{wk}$. Fish were placed in arenas at 16:00 h on Friday and then fed at 16:00 h on Sunday. Beginning on Monday (Day 1) observations were taken every $15 \mathrm{~min}$ between 09:00 and 16:00 h, and continued through Friday (Day 5), with another feeding on Thursday (Day 4) after 16:00 h. This cycle of feeding and observation was repeated the following week. This $4 \mathrm{~d}$ period between feedings was chosen after preliminary experiments had indicated that halibut of this age required $4 \mathrm{~d}$ after a large meal before they would again actively begin searching for food. Each fish was scored on its habitat location (sand or sponge side), $\%$ burial (scored $0,20,40,60,80$ or $100 \%)$ and body position ( 1 = body flat on sand, $2=$ head elevated, $3=$ forward half of body elevated). Fish were not measured at the end of this experiment, but were measured approximately 4 wk later during the predation trials. Data were summed for each day and then analyzed for effects of habitat, day and week using log-linear models (Fienberg 1980). Burial and body-position scores were averaged by day, then analyzed for day and week effects with repeated-measure analysis of variance (ANOVA) (Hicks 1982). Body- 
position data required rank transformation to meet ANOVA assumptions.

Predation experiment. Trials were conducted in the same $2.9 \mathrm{~m}$ arenas at $9^{\circ} \mathrm{C}( \pm 1)$. In these trials the entire bottom of each arena was covered either with $3 \mathrm{~cm}$ of sand, or sand plus sponge. The sand was raked smooth $48 \mathrm{~h}$ prior to trials, and then, for sponge trials, 104 sponges were dispersed in an approximately uniform pattern. This produced the same sponge density, coverage and interstructural spaces (i.e. distance between adjacent sponges) as in the preference trials. Interstructural spaces, measured from a randomly chosen trial, averaged $12.5 \mathrm{~cm}(\mathrm{SD}=2.7)$. As in prior experiments, sponge coverage extended to the walls of the arena, thereby preventing either predator or prey from avoiding sponges by swimming around the arena's perimeter. Next, a vertical partition, with small holes to allow water exchange, was lowered to divide each arena into halves. With the partition in place, 2 Age-2 halibut predators, which had been starved for $48 \mathrm{~h}$, were released into one side of each arena. Prior $(4 \mathrm{~h})$ to initiation of trials, prey (either 20 Age-0 halibut or rock sole that had been starved for $48 \mathrm{~h}$ ) were measured (total length) and released into the opposite side from the predators. These starvation periods for predators and prey were consistent with those used in the prior habitat-preference studies. Trials were initiated at 13:00 $\mathrm{h}$ by raising the partition and exposing the Age0 prey to the Age-2 halibut predators. All trials were videotaped from overhead during the $6 \mathrm{~h}$ prior to lights-off (19:00 h) and for an additional $6 \mathrm{~h}$ beginning at 07:00 h (lights-on) the following morning. Preliminary investigations had revealed that Age-2 halibut predators were unsuccessful at capturing prey during the nighttime hours (author's unpubl. data). Trials were terminated the next day at 13:00 $\mathrm{h}$ by lowering the partition and removing the predators. Then the water level was lowered to $\sim 10 \mathrm{~cm}$ and prey were recovered, enumerated and re-measured. Predator total lengths were also measured. Neither prey nor predators were used again in subsequent trials. We conducted 5 replicate trials for Age-0 halibut in the sponge habitat and for Age-0 rock sole in both sand and sponge habitats. Only 4 trials were conducted for Age-0 halibut in the sand habitat due to a shortage of Age-0 fish. Total fish length ranged from 39 to $75 \mathrm{~mm}$ for halibut $(\bar{x}=57)$ and 40 to $68 \mathrm{~mm}$ for Age-0 rock sole $(\bar{x}=50)$, such that rock sole were, on average, $7 \mathrm{~mm}$ smaller than halibut $\left(F_{[5,60]}=67.2, \mathrm{p}<0.001\right)$. This reflects the inherently slower growth rate characteristic of rock sole, compared to halibut (authors's unpubl. data). Total fish lengths did not differ between habitats $\left(F_{[1,15]}=0.00, \mathrm{p}=0.994\right)$. Rock sole that survived the $24 \mathrm{~h}$ predation trials were, on average, $2 \mathrm{~mm}$ longer than fish entering the trials (paired $t_{9}=-3.04, \mathrm{p}=$
0.014). Similarly, there was a trend for halibut to be 6 mm longer at the end of trials, although this was not statistically significant (paired $t_{6}=-2.15, \mathrm{p}=0.076$ ). Given the size range of prey available, we considered this degree of size-selectivity by the Age-2 halibut predators as trivial and assume it had no confounding effects upon other factors examined in this study. Total length for Age-2 halibut predators ranged from 260 to $335 \mathrm{~mm}(\bar{X}=297, \mathrm{SD}=15)$, with no differences between prey-species treatments $\left(F_{[1,15]}=0.20, \mathrm{p}=\right.$ $0.660)$, habitat $\left(F_{[1,15]}=0.01, \mathrm{p}=0.911\right)$ or their interaction $\left(F_{[1,15]}=1.49, \mathrm{p}=0.241\right)$. Mean halibut width was $9.6 \mathrm{~cm}(\mathrm{SD}=0.80)$.

One of the halibut-sponge trials was eliminated from subsequent analysis when review of videotapes indicated that neither predator moved during the daylight periods of the $24 \mathrm{~h}$ trial; 0 prey were consumed in this trial. The remaining trials were analyzed by ANOVA, examining the effects of prey species and habitat upon the number of prey consumed. Predator activity was quantified for the $12 \mathrm{~h}$ (13:00 to 19:00 h and $07: 00$ to $13: 00 \mathrm{~h}$ ) of trials that were videotaped by scoring during 2 min focal periods at 15 min intervals. Scores ranged from 0 to 2 ( 0 if neither predator moved, 1 if a single predator moved, 2 if both moved). Movement was defined as displacement by at least 1 body length during the $2 \mathrm{~min}$ focal period. Scores were summed over $2 \mathrm{~h}$ periods, multiplied by 100 and then divided by 16 (the highest possible score for a $2 \mathrm{~h}$ period) to arrive at a \% activity measure. Since observations indicated that movement was associated with foraging, this activity measure was assumed to be a surrogate for foraging activity. Although these data were rendered homoscedastic by rank transformation, they were slightly skewed, i.e. non-normally distributed, as indicated by visual inspection of a rankit plot. Since this deviation from normality was relatively modest, we assumed it would have minimal influence upon F-tests (Sokal \& Rohlf 1969), and data were analyzed by repeated-measures ANOVA (Hicks 1982). We also summed the raw activity scores over the entire $12 \mathrm{~h}$ period to arrive at an index (max. value $=96$ ) of overall foraging activity. Prey consumption was divided by overall foraging activity to arrive at an estimate of consumption unit-effort ${ }^{-1}$.

We quantified the rate of encounter between predators and prey in each trial. Since trials started with 20 prey on one side of the arena, we quantified encounter rates while the predator was foraging on that side. Age-2 halibut utilized a saltatory search mode, and pauses of $30 \mathrm{~s}$ or more were not uncommon; however, if a predator buried, foraging was considered to have ceased. Quantification of encounter rates ended for each trial when the predators had together encountered 10 prey. This assured that prey density on the 
'prey side' was not greatly depressed during this period of quantification. An encounter was considered to have occurred when (1) a prey flushed in response to a predator's approach, (2) a predator detected and stalked a stationary prey or (3) ambushed a moving prey, or (4) was attracted to and joined in the pursuit of a prey engaged by the other predator. Encounter rates were analyzed with ANOVA (Sokal \& Rohlf 1969). For flush encounters, which constituted $82 \%$ of total encounters, we measured the distance between predator and prey at initiation of the flush, recorded whether or not the predator initiated pursuit, the duration of pursuits, as well as the pursuit outcome (prey capture or escape). Since whether or not prey were pursued and the outcome of pursuits is categorical, these data were pooled by habitat and prey species and analyzed with log-linear models.

We also quantified measures of predator searchbehavior, including overall predator search-speed. Since search often included periods when a fish paused, i.e. temporary lack of movement, we further quantified the frequency of pauses $(<1 \mathrm{~cm}$ movement during $5 \mathrm{~s}$ ), the \% time actively moving, and speed during movement. These data were calculated from digitized movement tracts made during each of five 2 min focal periods. Focal periods were chosen to exclude encounters with prey and periods of prey pursuit or handling. As a consequence, we were able to consider foraging activity by predators throughout the entire arena, not just for the prey side of the arena. All focal periods occurred during the first $30 \mathrm{~min}$ subsequent to the first encounter between predators and prey. While we attempted to allocate focal periods to each of the 2 predators, in some trials one predator was inactive while the other actively foraged and consumed prey. As a result, the extent to which focal periods represented the activity of one or both predators varied between trials. Data for the 5 focal periods were averaged by trial and analyzed with ANOVA.

\section{RESULTS}

\section{Habitat preference}

Sub-yearling (Age-0) halibut demonstrated a strong preference for the sponge habitat (Fig. 1). In 7 of 8 trials, when given the choice between bare sand and sand with $16 \%$ sponge coverage, more Age-0 halibut were recovered from the sponge side of the arena after $24 \mathrm{~h}_{\text {; }}$ in 1 trial this pattern was reversed. Despite this heterogeneity in trials $(G=16.00, \mathrm{df}=7, \mathrm{p}=0.025)$, nearly twice as many halibut were recovered from the sponge than from the bare-sand side of the arenas. When trial data were pooled, the distribution of fish

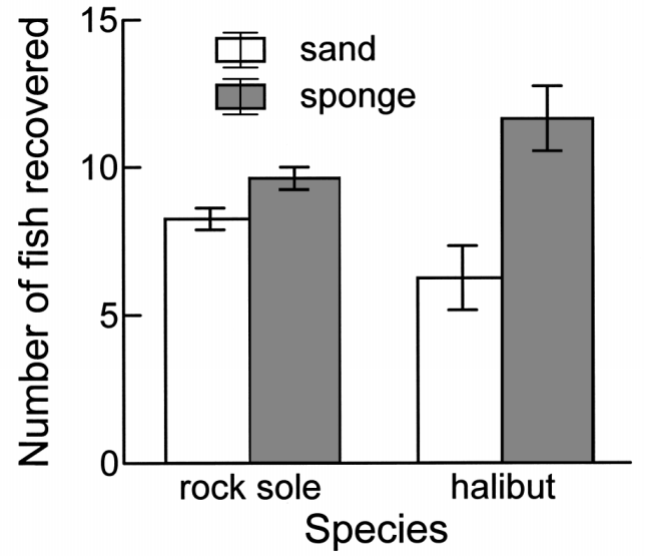

Fig. 1. Hippiglossus stenolepis and Lepodopsetta polyxystra. Mean number of Age- 0 flatfish $( \pm \mathrm{SE})$ recovered from sand and sand/sponge sides of $3 \mathrm{~m}$ arenas $24 \mathrm{~h}$ after their release; 18 fish released in each trial

between habitats differed significantly from the null hypothesis of a 50:50 distribution $(G=13.13, \mathrm{df}=1, \mathrm{p}<$ 0.001). In contrast to Age- 0 halibut, Age- 0 rock sole demonstrated little preference for the sponge habitat (Fig. 1), with nearly equal numbers recovered from the 2 habitats $(G=0.848, \mathrm{df}=1, \mathrm{p}=0.357)$. We did not record the positions of fishes relative to the center or walls of the arena.

For Age-2 halibut, we examined habitat preference in a smaller number of groups $(\mathrm{n}=5)$ over a $2 \mathrm{wk}$ period (Fig. 2a). Although these older fish were observed to more frequently occupy the sponge habitat (deviation from 50:50 null hypothesis for pooled data: $G=4687.80, \mathrm{df}=1, \mathrm{p}<0.001$ ), this preference appeared to vary with time since their last feeding. For both weeks, preference for sponge was high on Day 1 , the day after feeding, followed by declining preference for sponge through Day 4. Subsequent to the next feeding, which occurred at the end of Day 4, these groups demonstrated another high in their preference for sponge on Day $5(G=68.55, \mathrm{df}=4, \mathrm{p}<0.001)$. Although preference for sponge was greater during the second week than during the first $(G=42.27, \mathrm{df}=1$, $\mathrm{p}<0.001$ ), this pattern of habitat-preference relative to feeding was unchanged $(G=6.69, \mathrm{df}=4, \mathrm{p}=0.153)$. Although not quantified, we observed a tendency for halibut to be located in close proximity to the arena walls, particularly when they were on the bare sand side of the arena. In addition to habitat preference, feeding history influenced the burial behavior of Age-2 halibut (Fig. 2b). Although confounded somewhat by a day-week interaction $\left(F_{[4,36]}=3.34, \mathrm{p}=\right.$ 0.020 ), the dominant pattern was one in which fish buried more on the days immediately after feeding (Days 1 and 5) and buried less with increasing time since their last meal. This reduction in hiding/resting 

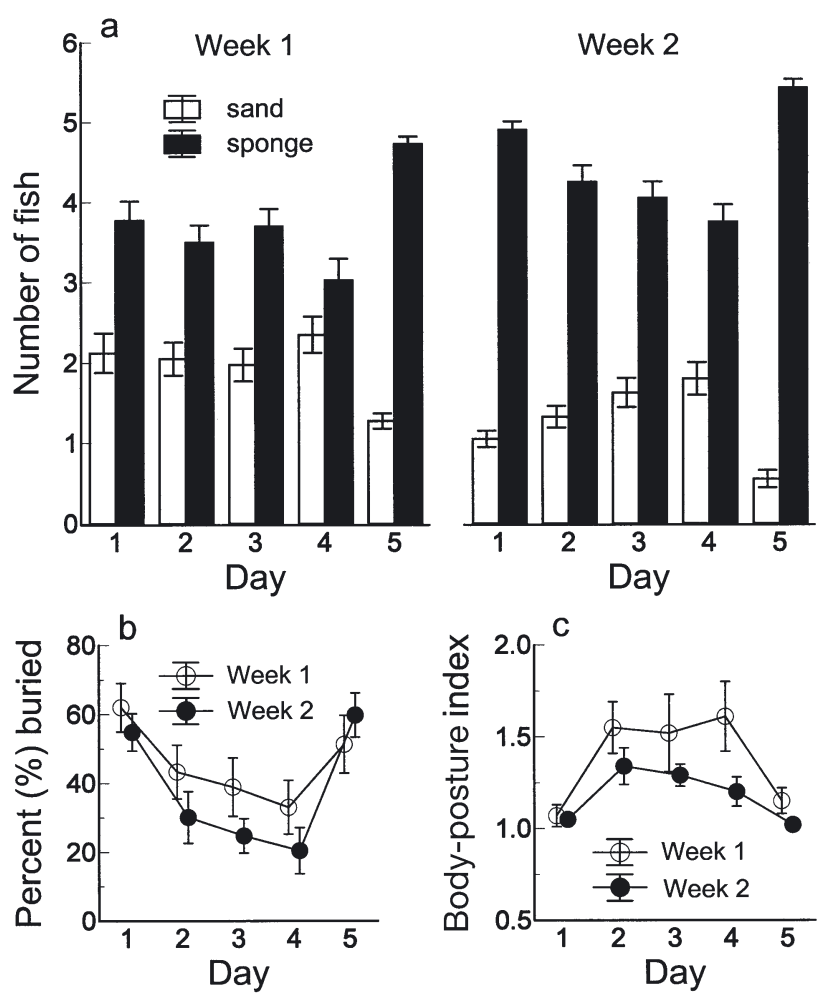

Fig. 2. Hippiglossus stenolepis. (a) Mean number of Age-2 halibut $( \pm \mathrm{SE}$ ) observed on sand and sand/sponge sides of $3 \mathrm{~m}$ arenas on Days 1 to 5 (Monday to Friday) over 2 wk; fish were fed to satiation the evening before Day 1 and again on the evening (after observations) of Day 4. (b) Mean percent burial of halibut $( \pm \mathrm{SE})$ on Days 1 to 5 , over $2 \mathrm{wk}$; burial scores for individual fish were 0 to $100 \%$ in $20 \%$ increments. (c) Mean body-posture index $( \pm \mathrm{SE})$; index scores were: 1 body flat on sediment; 2 head elevated; 3 forward half of body elevated. There were 6 fish in each arena

behavior with time since last feeding was also reflected in body posture (Fig. 2c). On the days immediately after feeding, fish tended to rest with their bodies flat on the sand (posture index $=1$ ). In the following days, fish increasingly rested with their heads raised off of the sediment (index $=2$ ) or with the entire front half of the body elevated (index $=3$ ), such that the mean posture index increased $\left(F_{[4,36]}=18.16, \mathrm{p}<0.001\right)$. The mean posture index was greater during the first than during the second week $\left(F_{[1,36]}=9.75, \mathrm{p}=0.004\right)$, with no day-week interaction $\left(F_{[4,36]}=1.54, \mathrm{p}=0.213\right)$.

\section{Predation experiment}

Halibut predators (Age-2) typically began foraging on the prey side of the arena within 30 min after the partition was raised. Predators utilized a saltatory search mode, alternating short forward movements $(10$ to $30 \mathrm{~cm}$ ) with brief pauses ( 3 to $15 \mathrm{~s}$ ). The arena walls appeared to influence predator search-patterns to some extent; upon encountering the wall, a predator would often swim along the wall for a distance before turning inward and continuing its search of the arena's interior. Over the course of the $24 \mathrm{~h}$ experiment, flatfish prey (Age-0) were consumed in greater numbers in bare sand than in the sponge habitat (Fig. 3) $\left(F_{[1,14]}=13.55, p=0.002\right)$. On a species level, Age-0 halibut were consumed in greater numbers than Age- 0 rock sole $\left(F_{[1,14]}=13.55, \mathrm{p}=0.002\right)$. These habitat and species effects were independent $\left(F_{[1,14]}=0.06\right.$, $p=0.805$ ). Despite the greater consumption of Age-0 halibut, the predators actually expended more effort while foraging for the Age-0 rock sole (Fig. 4), as demonstrated by their patterns of activity $\left(F_{[1,12]}=\right.$ $14.01, \mathrm{p}=0.003)$. Predators were also more active during the afternoon, after their first exposure to Age-0 flatfish prey, than they were the following morning $\left(F_{[5,60]}=12.24, \mathrm{p}<0.001\right)$. There were no significant habitat effects on predator activity $\left(F_{[1,12]}=1.66, \mathrm{p}=\right.$ 0.222 ), or higher-level interactions between habitat and prey species $\left(F_{[1,12]}=0.24, \mathrm{p}=0.634\right)$, habitat and time $\left(F_{[5,60]}=0.77, \mathrm{p}=0.578\right)$ or prey species and time $\left(F_{[5,60]}=0.46, \mathrm{p}=0.803\right)$. When consumption data for Age-0 flatfishes were corrected for predator activity, producing an index of prey consumption unit-effort ${ }^{-1}$, the differences between habitats and species were even more striking (Fig. 5). Prey consumption uniteffort ${ }^{-1}$ was approximately 2 times higher in the bare sand than in the sponge habitat $\left(F_{[1,14]}=11.67, \mathrm{p}=\right.$ 0.004 ), and 2 to 3 times higher for Age-0 halibut than rock sole $\left(F_{[1,14]}=30.07, \mathrm{p}<0.001\right)$. As in the uncorrected consumption data, there was no significant interaction between habitat and species $\left(F_{[1,14]}=0.92\right.$, $\mathrm{p}=0.355)$.

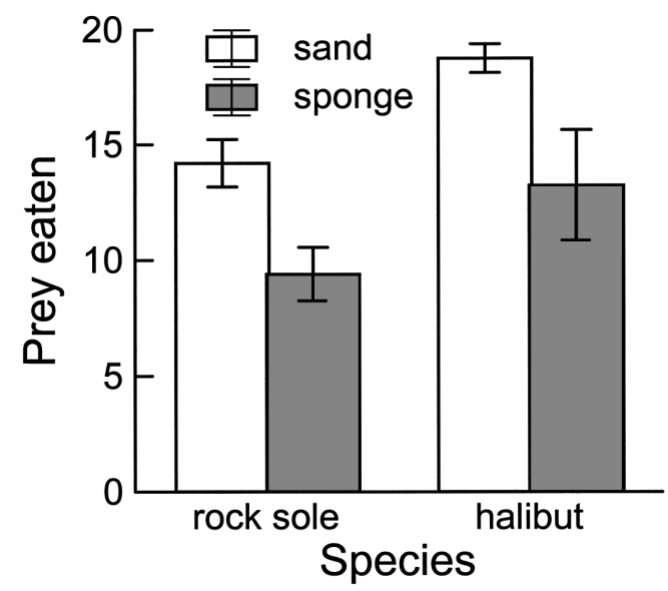

Fig. 3. Hippoglossus stenolepis foraging for H. stenolepis and Lepodopsetta polyxystra. Mean number of Age-0 halibut or rock sole $( \pm \mathrm{SE})$ consumed by Age- 2 halibut predators over $24 \mathrm{~h}$ in $3 \mathrm{~m}$ arenas with either sand or sand and sponge. Trials were initiated with 20 prey (either halibut or rock sole) and 2 predators 


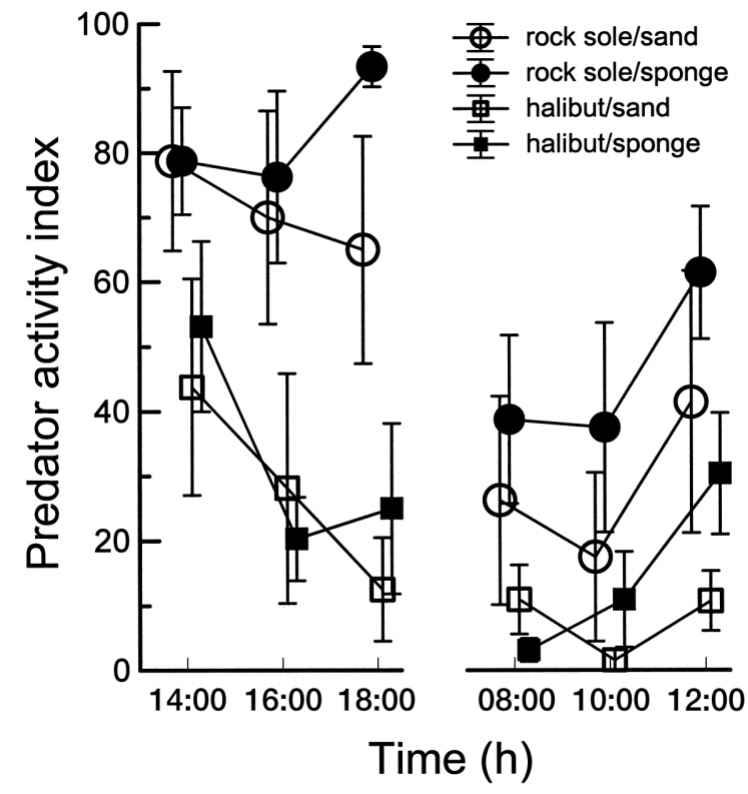

Fig. 4. Hippoglossus stenolepis foraging for $H$. stenolepis and Lepodopsetta polyxystra. Mean \% activity scores $( \pm \mathrm{SE})$ for Age-2 halibut predators at $2 \mathrm{~h}$ intervals when foraging for Age- 0 halibut or rock sole prey in either sand or sand and sponge. No observations were made during nighttime (19:00 to $07: 00 \mathrm{~h}$ )

These differences in vulnerability between habitats and species were attributable, in part, to predatorprey encounter rates (Fig. 6). The effect of habitat on encounter rates differed for the 2 flatfish prey species $\left(F_{[1,14]}=10.05, \mathrm{p}=0.001\right)$. Age-0 halibut were encountered by the predators nearly 4 times more frequently in the sand than in the sponge habitat (Tukey's HSD

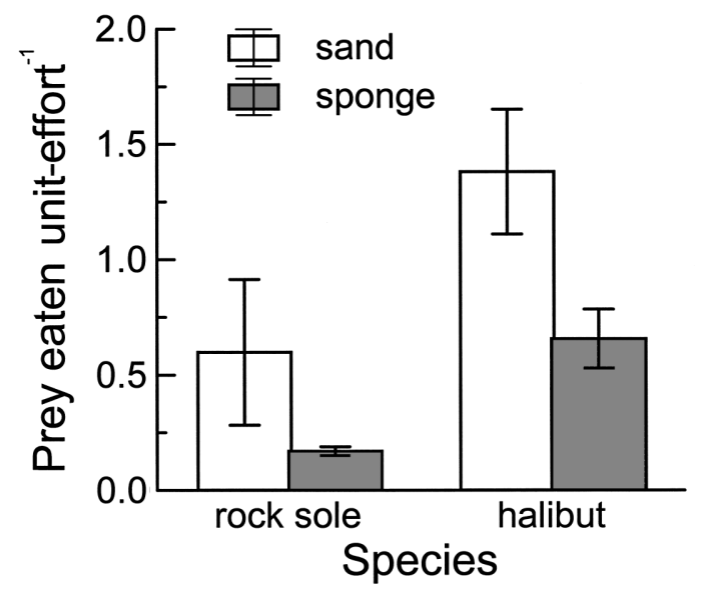

Fig. 5. Hippoglossus stenolepis foraging for $H$. stenolepis and Lepodopsetta polyxystra. Mean consumption unit-effort ${ }^{-1}( \pm \mathrm{SE})$ of Age-2 halibut predators foraging for Age-0 halibut or rock sole prey in either sand or sand and sponge. Consumption (Fig. 3) was corrected for effort using cumulative activity scores for predators (Fig. 4), under the assumption that prey were consumed during the daytime periods when activity was scored

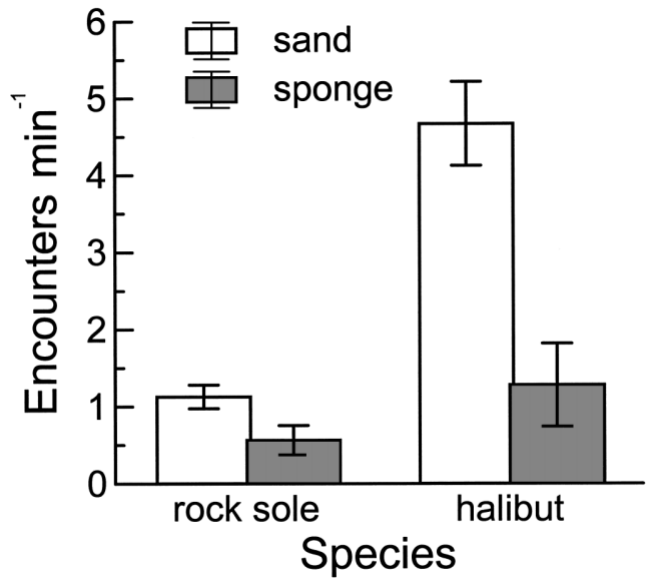

Fig. 6. Hippoglossus stenolepis foraging for $H$. stenolepis and Lepodopsetta polyxystra. Mean encounter rates (encounters $\mathrm{min}^{-1} ; \pm \mathrm{SE}$ ) between Age-2 halibut predators and Age-0 halibut or rock sole prey in either sand or sand and sponge

test, $\mathrm{p}<0.05)$. Although there was a trend for Age-0 rock sole to also be encountered more frequently in the sand habitat, this effect was not significant (Tukey's HSD test, $p>0.05$ ). Higher encounter rates in the sand habitat were attributable to differences in predator foraging behavior between habitats. During their saltatory search, predators in sand trials traversed approximately twice the distance per unit time as did predators in sponge trials (Fig. $7, F_{[1,14]}=11.93, \mathrm{p}=$ $0.004)$. This was a consequence of predators in sand trials pausing less frequently $\left(F_{[1,14]}=5.26, \mathrm{p}=0.038\right)$, such that they spent more time moving $\left(F_{[1,14]}=13.07\right.$, $\mathrm{p}=0.003)$. Further, while moving, they swam faster

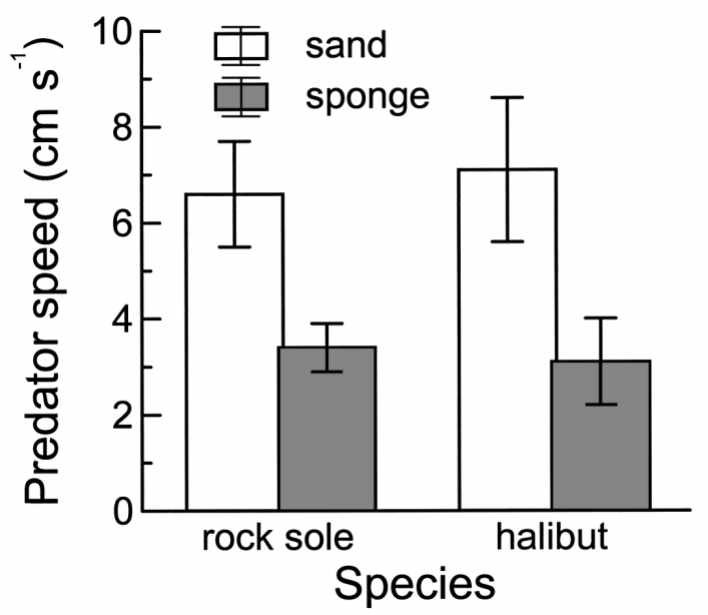

Fig. 7. Hippoglossus stenolepis foraging for $H$. stenolepis and Lepodopsetta polyxystra. Mean Age-2 halibut-predator speed $\left(\mathrm{cm} \mathrm{s}^{-1} ; \pm \mathrm{SE}\right.$ ) during active foraging for Age-0 halibut or rock sole prey in sand or sand and sponge. For each trial, predator speeds were measured during peaks of predator activity after first encounter with prey 
than predators in the sponge trials $\left(F_{[1,14]}=11.66, \mathrm{p}=\right.$ $0.004)$. There were no significant effects of prey species or interactive effects of habitat and prey species for any of these characteristics of predator-foraging (ANOVA, $\mathrm{p}>0.05$ for each).

In the majority of encounters (82\%) prey flushed in response to a predator's approach, whereas fewer encounters were characterized by detection of stationary prey $(5.1 \%)$, ambush of moving prey $(3.2 \%)$, or facilitation $(9.6 \%)$, that is, where a predator was attracted to and joined in the pursuit of a prey engaged by the other predator. Mean distance between predator and prey at flushing was $20.7 \mathrm{~cm}(\mathrm{SD}=14.4) \mathrm{cm}$. When flushed, there was a trend for rock sole to be pursued more often than halibut (\% pursuits: rock sole $=85 \%$, halibut $=70 \%, G=3.68$, df $=1, p=0.056)$. There was no effect of habitat upon likelihood of pursuit $(G=0.62, \mathrm{df}=1, \mathrm{p}=0.431$ ), or interactive effect between species and habitat $(G=0.04$, df $=1, \mathrm{p}=$ 0.841 ). In the $89 \%$ of pursuits for which outcome could be determined $(\mathrm{n}=114)$, rock sole were significantly more likely to be captured than were halibut (Fig. 8, $G=11.54, \mathrm{df}=1, \mathrm{p}<0.001)$. There was also a trend for a higher proportion of captures in sand trials than in sponge trials, although this pattern was not statistically significant $(G=2.93, \mathrm{df}=1, \mathrm{p}=0.087)$. Of the observed captures, $53 \%$ occurred at the arena walls as the prey fled upward along the wall.

During pursuits, some prey engaged in brief episodes of circling behavior. Rather than swimming away from the predator, the prey circled around to the predator's tail, which resulted in the predator rotating in an attempt to capture the prey. After several circling movements, and concomitant rotations by the predator, the prey would accelerate and swim in a straight

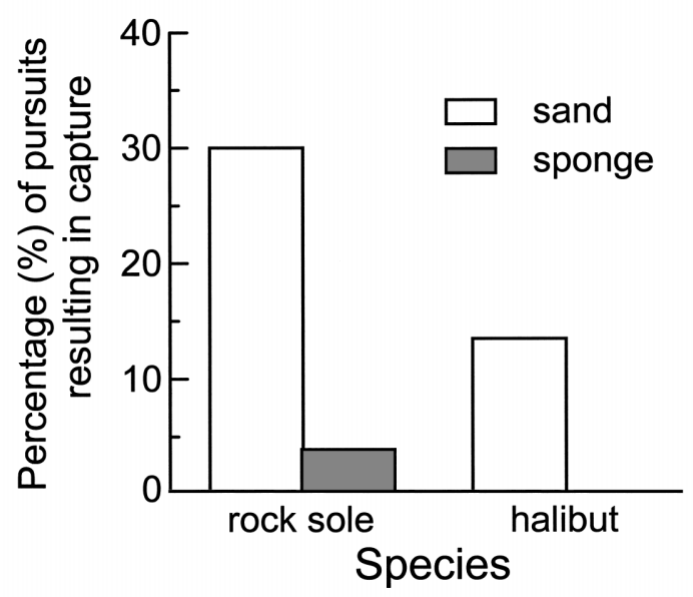

Fig. 8. Hippoglossus stenolepis foraging for $H$. stenolepis and Lepodopsetta polyxystra. Percentage of observed flush-pursuits resulting in capture for Age-2 halibut predators foraging for Age-0 halibut or rock sole prey in either sand or sand and sponge path away from the predator. Circling occurred more frequently during pursuits of rock sole $(14 \%)$ than of halibut $(2 \%)(G=6.08, \mathrm{df}=1, \mathrm{p}=0.014)$, and tended to be more prevalent in the sand (14\%) than the sponge $(5 \%)(G=3.54, \mathrm{df}=1, \mathrm{p}=0.060)$ habitat. There was no interactive effect of species and habitat upon the frequency of circling $(G=0.24$, df $=1, \mathrm{p}=0.624)$.

\section{DISCUSSION}

\section{Habitat-preference and vulnerability}

For Age-0 halibut and rock sole, features other than sediment characteristics, depth and temperature may play an important role in determining habitat quality. Halibut demonstrated a strong preference for occupying a structurally complex habitat, choosing sponge by an almost 2 to 1 margin. In contrast, rock sole showed a lesser and nonsignificant preference for sponge. A strong preference by Age-0 halibut for sponge habitat, as well as a lesser, but positive, preference by rock sole for sponge, has previously been documented (Stoner \& Titgen 2003). In recent field studies of shallow bays in and around Kodiak Island, Alaska, we found that both Age- 0 halibut and rock sole are in higher abundance where sediments have emergent structural features such as bivalve shells and other sessile macroinvertebrates (Stoner \& Titgen 2003). This suggests that sediments with these additional structural components may be perceived by juvenile halibut and rock sole as preferred habitats and, as indicated by our predation experiment, this may be attributable, in part, to decreased vulnerability to predators. Further, the degrees of preference demonstrated by these 2 species also concur with their relative vulnerabilities to predation: halibut were most vulnerable and showed the greatest preference, while rock sole, with a lower vulnerability, demonstrated lower habitat preference. Larger Age-0 winter flounder prefer structurally complex habitats (Manderson et al. 2000, Phelan et al. 2000) and, along with plaice (Wennhage 2002), are less vulnerable to predation in these habitats. The Age-2 halibut used as predators in this study also showed preference for a structurally complex habitat. With growing emphasis on understanding essential fish habitats for commercially important species, there is an accumulating body of evidence that models for flatfish habitat-suitability may need to incorporate a consideration of emergent structures of low-relief benthic habitats that impart structural complexity.

Although the negative effects of habitat structure upon predator foraging have been widely documented, the mechanisms have only infrequently been thoroughly examined. Structure can decrease predator 
foraging-rates by decreasing encounter rates with prey: (1) either the predator's ability to move through the habitat in search of prey is impeded, (2) the ability of the predator to detect prey is compromised, or (3) prey behavior changes such that the prey become less accessible to the predator. Alternatively, subsequent to encounter, habitat structure may interfere with pursuit and/or capture (Stoner 1982, Ryer 1988). Clearly, in our study, encounter rates were lower in the sponge than in the sand habitat. Bartholomew et al. (2000) suggested that the ratio of average interstructural space size to predator size $(\mathrm{Sp} / \mathrm{Pr})$ is a useful dimensionless measure of the extent to which the structure impedes predator movement. This model predicts that prey consumption will increase sigmoidally as $\mathrm{Sp} / \mathrm{Pr}$ decreases, with zero prey consumption at a ratio less than 1.0 where the predator is unable to move about the habitat to encounter prey. With an average interstructural space of 12.5 and an average halibut width of $9.6 \mathrm{~cm}, \mathrm{Sp} / \mathrm{Pr}$ averaged 1.3 for our experiments. As predicted for a $\mathrm{Sp} / \mathrm{Pr}$ of 1.3 , predator foraging was impeded, with predators pausing more frequently and moving more slowly as they maneuvered through the sponges. In addition to this generalized effect of habitat structure on search behavior, our observations indicate that variance in average interstructural space size may have created refuge patches in the sponge habitat that further restricted predator search. Although we attempted to spread out the sponges evenly in each trial, invariably there were small patches where 2 or 3 sponges were more closely spaced, as well as other areas where sponges were more sparse. It was apparent that the halibut predators avoided these higherdensity patches, choosing to move along 'paths of least resistance' where sponges were sparse, with the result that areas of the arenas often went unexplored. This, together with the decrease in predator search speed, indicates that impediment of predator search may be an important mechanism contributing to the refuge value of structurally complex habitats.

Surprisingly, we saw no evidence that detection impairment, i.e. visual obstruction of prey by sponges, played a role in the reduced rate of encounters in the sponge habitat. Most encounters entailed the flushing of prey and, if predators had detected fewer of these in the sponge trials, there should have been a lower incidence of pursuit; this was not the case. Although the average distance at which prey flushed $(20.7 \mathrm{~cm})$ was nearly twice the average distance between sponges $(12.5 \mathrm{~cm})$, it is likely that the prey were still visible as they passed between obstructions (sponges) in the predator's view. Had juvenile halibut or rock sole flushed at greater distances or had spontaneous movements by these prey been more frequent, such that ambush encounters were more frequent, we suspect that impairment of prey detection would have played a more significant role in this experimental system. Impairment of a predator's ability to detect prey in structured habitats can play an important role in predator-prey interactions, particularly where prey possess specific behavioral tactics to take advantage of habitat structure (Main 1987).

While impediment of predator search, an encounter process, contributed to lowered prey vulnerability in the sponge habitat, post-encounter processes also played a role. Once a predator engaged in pursuit, it was twice as likely to capture juvenile flatfish prey in the sand as opposed to the sponge habitat. Although this effect was not statistically significant $(p=0.087$ ), it was clear, while watching trials, that prey were often able to break off contact with the predator during flight through the sponge habitat. The ability of largemouth bass Micropterus salmoides to pursue the bluegill Lepomis macrochirus through submerged vegetation has been shown to decrease with increasing stem density (Savino \& Stein 1982). Structure decreases the predator's reactive distance, allowing initial escape responses to carry prey outside the predator's visual field. In this sense, structure is analogous to turbidity, where contrast degradation reduces predator reactive distance, facilitating prey escape (De Robertis et al. 2003). Therefore, the overall importance of pursuit limitations in various structured habitats will probably hinge on whether the structure magnifies existing prey escape-behaviors to a meaningful extent. Where prey possess meager escape capabilities that are not significantly facilitated by structure, encounter-rate processes alone will control reductions in prey vulnerability. Where prey have latent escape responses that are magnified by structure, a combination of encounter and post-encounter processes will define the degree to which habitat structure reduces prey vulnerability.

Preference for, or time spent in, refuge habitats may be influenced by various factors. Age-2 halibut preference for the structurally complex sponge habitat declined with increasing hunger. Similarly, fish buried less and adopted a more alert 'head-up' body posture as time since last feeding increased. We interpret this as indicative of a hunger-mediated trade-off between refuging and foraging; when satiated, fish tended to occupy the safer sponge habitat, but increasingly shifted to the riskier open-sand habitat as their hunger increased. This interpretation assumes that the fish (1) perceived open sand as providing a higher foraging return, but (2) at a higher risk of predation. The first of these assumptions is supported by our predation experiments: halibut consumed more Age-0 flatfishes in the open sand. With regard to the second, Age-2 halibut have not yet outgrown all predatory risk and 
would probably be less vulnerable to predation in a habitat containing emergent structure, as was demonstrated for Age-0 flatfish. Further, although these fish were not exposed to predation risk, our presence and activities, including periodic netting and handling of fishes, probably served as a surrogate source of risk, stimulating refuging behavior. Similar internal state modulation of the trade-off between refuging and foraging has been observed in other species: the Crucian carp Carassius carassius and the pink salmon Oncorhynchus gorbuscha also spend more time in risky but energetically profitable habitats when hungry (Magnhagen 1988, Pettersson \& Brönmark 1993) .

The starvation periods for Age- 2 and Age-0 flatfishes in the predation experiment were chosen so as to be the same as in the habitat-preference experiments, and almost certainly influenced our results. For example, had the predators been starved for a shorter period, they would have probably been more variable in their foraging activity and might have consumed fewer prey. Perhaps more importantly, hunger may have influenced the vulnerability of the prey. There were relatively few instances $(3.2 \%)$ where predators attacked prey that were moving, as might be expected were prey actively moving about in search of food. However, it is possible that, as in the Age-2 habitat-preference experiments, hunger resulted in the Age-0 prey spending more time resting on the sediment surface, as opposed to being buried, which may have influenced their tendency to flee when approached by a predator. This draws attention to how little is known regarding the behavior of flatfishes, and how internal motivation and external risks may play a part in behavioral processes such as burial, movement and vigilance.

\section{Differences in flatfish antipredator strategies}

Flatfishes are typically viewed as having a stereotypic predator avoidance strategy, yet our experiments demonstrate species-specific variation in this trait. Although our Age-0 halibut were, on average, $7 \mathrm{~mm}$ larger than the rock sole, they were more vulnerable to predation. This difference is attributable to behavior; halibut rely upon flight to elude predators, whereas rock sole use crypsis and tonic motion to avoid detection. When recovering prey from our predation trials, halibut would flush and flee at the approach of a dipnet or rake, whereas rock sole frequently had to be physically extracted from the sand. This difference in their behavioral response to disturbance reflects underlying differences in physical capabilities. Halibut have narrower and thicker bodies than rock sole, as well as a narrower caudal peduncle (Stoner \& Ottmar 2003), both attributes associated with fast swimming.
In contrast, rock sole have superior cryptic capabilities, enabling them to match their appearance to sediment more closely (Stoner \& Ottmar 2003). In our experiment, halibut were more prone to flight when they perceived an approaching predator, whereas rock sole were more likely to remain motionless and let the predator pass, regardless of habitat. These behavioral predispositions reflect the differing consequences of flight for the 2 species; once flushed, there was a greater likelihood that rock sole would be pursued and a greater likelihood that pursuit would result in capture, compared to halibut. Because they were less likely to escape a pursuing predator, rock sole were also more likely to engage in circling behavior, which we interpret to be a desperation tactic employed to escape a pursuer. These differences in antipredator behavior, which are based on physical capabilities, demonstrate that flatfish species possess a wider repertoire of strategies for dealing with predation than has been heretofore appreciated.

How structurally complex habitats function as predation refugia depends as much on prey behavior as the physical characteristics of the habitat. A variety of studies have shown that both vertebrate (Gilliam \& Fraser 1987, Newman \& Caraco 1987, Petranka et al. 1987) and invertebrate (Stein \& Magnusson 1976, Zaret \& Suffern 1976) prey are aware of predators and modify their distributions and/or foraging behavior to avoid predatory encounters. Furthermore, behavior patterns may differ between habitats. Early juveniles ( $<25 \mathrm{~mm}$ ) of the gastropod Strombus gigas are highly vulnerable to predation on bare sand, and remain buried during the day, emerging only at night to move about and feed (Sandt \& Stoner 1993). In contrast, these small juveniles are less vulnerable in turtlegrass Thalassia testudinum, and move about on the sediment surface day and night (Ray \& Stoner 1995). In our experiments we observed an interactive effect of prey species and habitat upon predator-prey encounter rates. We interpret this as an indication of a differential response to predator approach by Age-0 halibut in the 2 habitats, that is, they were more likely to flush in the open sand than they were in the sponge habitat. Age0 halibut may perceive that they are particularly vulnerable in the open sand, due to their inferior cryptic capability (compared to rock sole), and are therefore more likely to initiate flight than in a more structured habitat. This may also explain why halibut demonstrate a stronger preference for sponge than rock sole.

Our arenas did tend to curtail prey escape-behavior. While $91 \%$ of predator-prey encounters resulted in prey escape, of those resulting in capture, 53\% occurred along the perimeter of the arena, after prey swam upward along the arena wall during pursuit. Since halibut appear to rely upon flight to a greater 
extent than rock sole, particularly in the sand, this may have differentially magnified their mortality. It is perhaps inevitable that many extended pursuits, which entailed repeated short flight movements $(<2 \mathrm{~m})$ and reciprocal pursuit by the predator, ended along the perimeter of the arena. However, this was observed in both prey species and habitats, and if constraints on prey flight-behavior inflated mortality, we assume the effect was modest.

\section{Implications for ecosystems and fisheries}

Many historic fishing grounds have been fished for generations and, in some instances, annual effort on these grounds may be considerable. It has been estimated that 200 to $400 \%$ of the surface area of Georges Bank is subject to disturbance by bottom trawls and dredges annually (Auster et al. 1996). This can remove and/or dislodge sessile invertebrates such as sponges, bryozoans, ascidians and anthozoans that provide much of the structural complexity in these low-relief areas of the continental shelf (Collie et al. 1997, Freese et al. 1999, Kaiser et al. 2000, Pitcher et al. 2000). In the eastern Bering Sea, where both juvenile halibut and rock sole are abundant, large sessile invertebrates are significantly less abundant in trawled than in untrawled areas (McConnaughey et al. 2000). Such reductions in bottom structure appear to be a common consequence of intensive trawling (Van Dolah et al. 1987, Thrush et al. 1998, Freese et al. 1999). Our laboratory experiments, along with prior field and laboratory work (Stoner \& Titgen 2003), indicate that Age-0 yr halibut and rock sole are likely to be found at higher density in low-relief habitats that have emergent structure. Some of the highest densities of sessile invertebrates known for the Bering Sea, as measured by survey-trawl bycatch, occur in a $390000 \mathrm{~km}^{2}$ area that has a long history of closure to towed gear (see: www.afsc.noaa.gov/groundfish/HAPC/EBScontents.htm). This area is also considered to be a primary nursery ground for Pacific halibut (Best \& Hardman 1982). The sponge coverage utilized in our study $(16 \%)$ represents an extrapolation of this invertebrate bycatch, making assumptions regarding capture efficiency and distributional patchiness, and probably represents the extreme of the natural situation in the North Pacific. However, structural coverage to this extent is not without precedent. In video surveys of waters around Kodiak Alaska, we have observed areas of bottom with bivalve shells and infaunal bioturbation/defecation mounds that approximate this coverage, as well as expansive areas of polychaete tubes with denisites exceeding thousands $\mathrm{m}^{-2}$ (author's unpubl. data). Similarly, on Georges Bank in the northwest Atlantic, poly- chaete Filograna implexa tubes form structures of similar size, shape and coverage as the sponge utilized in our experiments (Collie et al. 1997). Given that such habitat features are often patchily distributed, a direct effect of their partial or complete removal would probably be reduced aggregation of juveniles in areas of preferred habitat. Predation rates upon juvenile flatfishes may also increase as the refuge value of these habitats declines. This potential linkage between structure and nursery function has been suggested for roundfish (Tupper \& Boutilier 1995, Lindholm et al. 1999), other flatfishes (Manderson et al. 2000, Wennhage 2002) and crustaceans (Heck \& Thoman 1984, Orth \& van Montfrans 1987, Stevens \& Kittaka 1998), and may constitute a principle ecological framework for understanding the effects of habitat destruction on benthic communities and fisheries. Although studies like this may hint at the importance of emergent structure, ultimately, the extent to which it influences significant control over juvenile fish survival and abundance requires further detailed studies of predator-prey interactions across a range of structure types. For example, a lower-relief structure such as bivalve shell might be expected to have less influence on predator-prey interactions, as it would be less likely to impede predator search and pursuit. Similarly, predators with differing physical constraints, behavior and foraging strategies may be affected differently by habitat structure. Research must also address predator-prey interactions at lower densities/coverages of emergent structure, which may be more ubiquitous in nature. Lastly, a more thorough knowledge of the abundance and distributions of these emergent structures in the environment is needed.

\section{Conclusions}

There is an accumulating body of evidence that emergent features of low-relief benthic habitats may play an important role in the ecology of some juvenile flatfish species. Both Age-0 halibut and rock sole were more vulnerable to predation in the open sand habitat than in a sand habitat with $16 \%$ sponge cover. These juvenile flatfishes were consumed less frequently by predators in the sponge habitat because (1) predator search was impeded, and (2) during pursuit, juvenile flatfishes tended to escape more often in the sponge. Although mortality rates in these experiments were relative, and should not be taken as indicative of actual rates in the field, they do suggest that reduced juvenile mortality may be a consequence of emergent structure in low-relief benthic habitats. The functional role of emergent structure needs to be further clarified through integrated field and laboratory studies to 
determine if it constitutes an important characteristic of the essential habitat of these species. Further, we need to know whether the partial or complete removal of emergent structures from low-relief benthic habitats may have negative implications for the functionality of these habitats as nurseries for juvenile flatfishes. From this work it has also become apparent that, behaviorally speaking, a flatfish is not a flatfish. There were significant differences between Age-0 halibut and rock sole with regards to predation vulnerability and antipredator behavior. Halibut were generally more vulnerable to predation (which may explain their greater preference for occupying structured habitats) than to rock sole. Juvenile rock sole rely upon crypsis and motionlessness to reduce encounters with predators, whereas juvenile halibut, with their narrower, more powerful bodies, rely more upon flight and are more likely to escape a pursuing predator than are rock sole.

Acknowledgements. We thank Eric Munk for logistical support and his assistance with collections of juvenile flatfishes in Kodiak. Brad Stevens, Robert Otto and the Borough of Kodiak provided laboratory space for holding fishes in Kodiak. We thank Michele Ottmar, Erick Sturm, Paul Iseri, Scott Haines and Mara Spencer for their assistance with laboratory experimentation and data acquisition, and Cindy Sweitzer for manuscript preparation. Thomas Hurst provided useful comments on an early draft of this manuscript. This work was funded in part by a grant from the North Pacific Research Board.

\section{LITERATURE CITED}

Abookire AA, Norcross BL (1998) Depth and substrate as determinants of distribution of juvenile flathead sole (Hippoglossoides elassodon) and rock sole (Pleuronectes bilineatus), in Kachemak Bay, Alaska. J Sea Res 39:113-123

Amezcua F, Nash RDM (2001) Distribution of the order Pleuronectiformes in relation to the sediment type in the North Irish Sea. J Sea Res 45:293-301

Auster PJ, Malatesta RJ, Langton RW, Watling L and 5 others (1996) The impacts of mobile fishing gear on seafloor habitats in the Gulf of Maine (northwest Atlantic): implications for conservation of fish populations. Rev Fish Sci 4: 185-202

Bartholomew A, Diaz RJ, Cicchetti G (2000) New dimensionless indices of structural habitat complexity: predicted and actual effects on a predator's foraging success. Mar Ecol Prog Ser 206:45-58

Best EA, Hardman WH (1982) Juvenile halibut surveys, 1973-1980. Tech Rep No. 20. International Pacific Halibut Commission, Seattle, WA

Collie JS, Escanero GA, Valentine PC (1997) Effects of bottom fishing on the benthic megafauna of Georges Bank. Mar Ecol Prog Ser 155:159-172

De Robertis A, Ryer CH, Veloza A, Brodeur RD (2003) Differential effects of turbidity on prey consumption of piscivorous and planktivorous fish. Can J Fish Aquat Sci 60: 1517-1526

Fienberg SE (1980) The analysis of cross classified categorical data. MIT Press, Cambridge, MA
Freese L, Auster PJ, Heifetz J, Wing BL (1999) Effects of trawling on seafloor habitat and associated invertebrate taxa in the Gulf of Alaska. Mar Ecol Prog Ser 182:119-126

Gibson RN, Robb L (1992) The relationship between body size, sediment grain size and the burying ability of juvenile plaice, Pleuronectes platessa L. J Fish Biol 40:771-778

Gibson RN, Robb L (2000) Sediment selection in juvenile plaice and its behavioural basis. J Fish Biol 56:1258-1275

Gilliam JF, Fraser DF (1987) Habitat selection under predation hazard: test of a model with foraging minnows. Ecology 68:1856-1862

Heck KL Jr, Thoman TA (1984) The nursery role of seagrass meadows in the upper and lower reaches of the Chesapeake Bay. Estuaries 7:70-92

Hicks C (1982) Fundamental concepts in the design of experiments. Holt Rinehart \& Winston, New York

Howell PT, Molnar DR, Harris RB (1999) Juvenile winter flounder distribution by habitat type. Estuaries 22: 1090-1095

Jager Z, Kleef L, Tydeman P (1993) The distribution of 0 -group flatfish in relation to abiotic factors on the tidal flats in the brackish Dollard (Ems estuary, Wadden Sea). J Fish Biol 43:31-43

Kaiser MJ, Spence FE, Hart PJB (2000) Fishing-gear restrictions and conservation of benthic habitat complexity. Conserv Biol 14:1512-1525

Lindholm JB, Auster PJ, Kaufman LS (1999) Habitat-mediated survivorship of juvenile (0-year) Atlantic cod Gadus morhua. Mar Ecol Prog Ser 180:247-255

Magnhagen C (1988) Predation risk and foraging in juvenile pink (Onchrychus gorbuscha) and chum salmon (O. keta). Can J Fish Aquat Sci 45:592-596

Main KL (1987) Predator avoidance in seagrass meadows: prey behavior, microhabitat selection and cryptic coloration. Ecology 68:170-180

Manderson JP, Phelan BA, Stoner AW, Hilbert J (2000) Predator-prey relations between Age-1+ summer flounder (Paralichthys dentatus, Linnaeus) and Age-0 winter flounder (Pseudopleuronectes americanus, Walbaum): predator diets, prey selection, and effects of sediments and macrophytes. J Exp Mar Biol Ecol 251:17-39

McConnaughey RA, Smith KR (2000) Associations between flatfish abundance and surficial sediments in the eastern Bering Sea. Can J Fish Aquat Sci 57:2410-2419

McConnaughey RA, Mier KL, Dew CB (2000) An examination of chronic trawling effects on soft-bottom benthos of the eastern Bering Sea. ICES J Mar Sci 57:1377-1388

Moles A, Norcross BL (1995) Sediment preference in juvenile Pacific flatfishes. Neth J Sea Res 34:177-182

Newman JA, Caraco T (1987) Foraging, predation hazard and patch use in gray squirrels. Anim Behav 35:1804-1813

Norcross BL, Mueter FJ (1999) The use of an ROV in the study of juvenile flatfish. Fish Res 39:241-251

Norcross BL, Müter FJ, Holladay BA (1997) Habitat models for juvenile pleuronectids around Kodiak Island, Alaska. Fish Bull US Natl Mar Fish Serv 95:504-520

Norcross BL, Blanchard A, Holladay BA (1999) Comparison of models for defining nearshore flatfish nursery areas in Alaskan waters. Fish Oceanogr 8:50-67

Orth RJ, van Montfrans J (1987) Utilization of a seagrass meadow and tidal marsh creek by blue crabs Callinectes sapidus. I. Seasonal and annual variations in abundance with emphasis on post-settlement juveniles. Mar Ecol Prog Ser 41:283-294

Petranka JW, Kats LB, Sih A (1987) Predator-prey interactions among fish and larval amphibians: use of chemical cues to detect predatory fish. Anim Behav 35:420-425 
Pettersson LB, Brönmark C (1993) Trading off safety against food: state dependent habitat choice and foraging in crucian carp. Oecologia 95:353-357

Phelan BA, Goldberg R, Bejda AJ, Pereira J and 5 others (2000) Estuarine and habitat-related differences in growth rates of young-of-the-year winter flounder (Pseudopleuronectes americanus) and tautog (Tautoga onitis) in three northeastern US estuaries. J Exp Mar Biol Ecol 247:1-28

Phelan BA, Manderson JP, Stoner AW, Bejda AJ (2001) Sizerelated shifts in the habitat associations of young-of-theyear winter flounder (Pseudopleuronectes americanus): field observations and laboratory experiments with sediments and prey. J Exp Mar Biol Ecol 257:297-315

Pitcher CR, Poiner IR, Hill BJ, Burridge CY (2000) Implications of the effects of trawling on sessile megazoobenthos on a tropical shelf in northeastern Australia. ICES J Mar Sci 57:1359-1368

Ray M, Stoner AW (1995) Growth, survivorship, and habitat choice in a newly settled seagrass gastropod, Strombus gigas. Mar Ecol Prog Ser 123:83-94

Rogers SI (1992) Environmental factors affecting the distribution of sole (Solea solea L.) within a nursery area. Neth J Sea Res 29:153-161

Ryer CH (1988) Pipefish foraging: effects of fish size, prey size and altered habitat complexity. Mar Ecol Prog Ser 48: $37-45$

Ryer CH, van Montfrans J, Orth RJ (1990) Utilization of a seagrass meadow and tidal marsh creek by blue crabs Callinectes sapidus. II. Spatial and temporal patterns of molting. Bull Mar Sci 46:95-104

Sandt VJ, Stoner AW (1993) Ontogenetic shift in habitat by early juvenile queen conch, Strombus gigas-patterns and potential mechanisms. Fish Bull Fish Wildl Serv US 91:516-525

Savino J, Stein RA (1982) Predator-prey interaction between largemouth bass and bluegills as influenced by simulated, submersed vegetation. Trans Am Fish Soc 111: 255-266

Sogard SM (1992) Variability in growth rates of juvenile fishes in different estuarine habitats. Mar Ecol Prog Ser 85:35-53

Sogard SM, Able KW (1991) A comparison of eelgrass, sea lettuce macroalgae, and marsh creeks as habitats for epibenthic fishes and decapods. Estuar Coast Shelf Sci 33: 501-519

Sokal RR, Rohlf FJ (1969) Biometry: the principles and practice of statistics in biological research. WH Freeman, San Francisco, CA

Editorial responsibility: Kenneth Heck (Contributing Editor), Dauphin Island, Alabama, USA
Stein RA, Magnusson JJ (1976) Behavioral response of crayfish to a fish predator. Ecology 57:751-761

Stevens BJ, Kittaka J (1998) Postlarval settling behavior: substrate preference, and time to metamorphosis for red king crab Paralithodes camtschaticus. Mar Ecol Prog Ser 167: 197-206

Stoner AW (1982) The influence of benthic macrophytes on the foraging behavior of pinfish, Lagodon rhomboides (Linnaeus). J Exp Mar Biol Ecol 58:271-284

Stoner AW, Abookire AA (2002) Sediment preferences and size-specific distribution of young-of-the-year Pacific halibut in an Alaska nursery. J Fish Biol 61:540-559

Stoner AW, Ottmar ML (2003) Relationships between sizespecific sediment preferences and burial capabilities in juveniles of two Alaska flatfishes. J Exp Mar Biol Ecol 282: 85-101

Stoner AW, Titgen RH (2003) Biological structures and bottom type influence habitat choices made by Alaska flatfishes. J Exp Mar Biol Ecol 292:43-59

Stoner AW, Manderson JP, Pessutti JP (2001) Spatially explicit analysis of estuarine habitat for juvenile winter flounder: combining generalized additive models and geographic information systems. Mar Ecol Prog Ser 213:253-271

Swartzman G, Huang C, Kaluzny S (1992) Spatial analysis of Bering Sea groundfish survey data using generalized additive models. Can J Fish Aquat Sci 49:1366-1378

Thrush SF, Hewitt JE, Cummings VJ, Dayton PK and 6 others (1998) Disturbance of the marine benthic habitat by commercial fishing: impacts at the scale of the fishery. Ecol Appl 8:866-879

Thrush SF, Schultz D, Hewitt JE, Talley D (2002) Habitat structure in soft-sediment environments and abundance of juvenile snapper Pagrus auratus. Mar Ecol Prog Ser 245:273-280

Tupper M, Boutilier RG (1995) Effects of habitat on settlement, growth, and postsettlement survival of Atlantic cod (Gadus morhua). Can J Fish Aquat Sci 52:1834-1841

Van Dolah RF, Wendt RH, Nicholson N (1987) Effects of a research trawl on a hard-bottom assemblage of sponges and corals. Fish Res 5:39-54

Wennhage H (2002) Vulnerability of newly settled plaice (Pleuronectes platessa L.) to predation: effects of habitat structure and predator functional response. J Exp Mar Biol Ecol 269:129-145

Zaret TM, Suffern JS (1976) Vertical migration in zooplankton as a predator avoidance mechanisms. Limnol Oceanogr 21:804-813

Submitted: March 7, 2003; Accepted: November 3, 2003 Proofs received from author(s): March 1, 2004 